\title{
Evolutionary micro-dynamics and changes in the economic structure
}

\author{
André Lorentz • Maria Savona
}

Published online: 7 May 2008

(C) The Author(s) 2008

\begin{abstract}
The paper aims to account for the empirical stylized facts related to changes in sectoral structures that have led to the growth of services in most advanced countries over recent decades. A growth model with evolutionary micro-founded structural change is developed, which formalizes the role of technical change and changes in intermediate demand as they affect the evolution of the sectoral composition of the economy and macro-economic growth. The simulated results are based on the use of the actual data, including InputOutput coefficients in the case of Germany. Three scenarios are identified, which account for the effects of a set of key parameters on changes in the structure of the economy.
\end{abstract}

Keywords Economic growth - Structural change - Growth of services • Evolutionary micro-foundation $\cdot$ Input-output

JEL Classification $\mathrm{E} 11 \cdot \mathrm{L} 16 \cdot \mathrm{O} 14 \cdot \mathrm{O} 33 \cdot \mathrm{O} 41$

The authors are grateful to M. Valente for suggestions and technical advice. The paper benefited from comments and suggestions from E. Andersen, R. Schettkat, U. Witt and participants in the 11th International J.A. Schumpeter Society Conference held in Nice in 2006, and those of two anonymous referees. This work was carried out during Maria Savona's stay at BETA, Université Louis Pasteur, Strasbourg as a Centre National de la Recherche Scientifique Post-doc Fellow. The usual disclaimers apply.

A. Lorentz $(\bowtie)$

Evolutionary Economics Group, Max Planck Institute of Economics,

Kahlaische Strasse 10, 07745 Jena, Germany

e-mail: lorentz@econ.mpg.de

M. Savona

Faculté des Sciences Economiques et Sociales, Université Lille 1, Lille, France

e-mail: Maria.Savona@univ-lille1.fr 


\section{Introduction}

The debate around the determinants and economic impact of tertiarization is age-old (Fisher 1935, 1945; Clark 1940) and has always been somewhat controversial. On the one hand, the 'optimists' (for instance Fourastié 1949) looked at the growing employment share of services as being an indicator of a further stage of development in advanced economies following mass industrialization, as well as a symptom of an increasing income- and consumptioncapacity. On the other hand, a later, large community of 'sceptical' scholars (Baumol and Bowen 1966; Baumol 1967; Kaldor 1966; Fuchs 1968) pointed to the 'collateral effects' of the growth of services in terms of de-industrialization, which translated into (s)lower aggregate productivity growth.

Since the beginning of this debate, the growth of services has become an empirical stylized fact, which represents the most relevant case of change in the economic structure. (For a recent reassessment, see Parrinello 2004; Schettkat and Yocarini 2006). Yet, it is still the object of lively debate, as far as its determinants are concerned.

A recent collection of contributions on the economics of services (ten Raa and Schettkat 2001) in fact refers to the 'service paradox' as a still unresolved issue in the economic literature. (See also Appelbaum and Schettkat 1999; Baumol 2001; Pugno 2006). The 'paradox' consists of the empirical fact that advanced economies are still experiencing sustained growth rates in real output and employment in the service industries, despite the trend towards increasing input costs and prices.

Baumol recently confirmed his position with respect to the 'service paradox' (p.1 Baumol 2008):

I have repeatedly argued that the rising real prices that constitute the cost disease that is named in my honour cannot force society to give up the patterns of consumption to which it is habituated and that it prefers now or used to. Neither health care nor education are condemned to deterioration in quality and decline in quantity by their rising real prices. For the nearly universal phenomenon of rising productivity means we can afford them, indeed, that we can even afford steady expansion in the amounts supplied and consumed, despite their disturbingly persistent and substantial rates of cost increase.

Further, he points to the very essence of the process of structural changecross-sectoral differences in productivity growth rates - by reformulating the concept of 'cost disease' named in his honor in terms of 'Baumol's Fourth Tautology' (Baumol 2008):

'Since rates of labour-saving productivity growth are uneven, the growth in some activities must be below average'

Baumol refers to the two specific empirical facts that represent the main drivers of tertiarization processes. On the one hand patterns of (final) consumption of services have been shown to be rather price-inelastic. On the 
other hand, the uneven rate of productivity gains across sectors are behind the existence of a 'paradox'.

Indeed, since the debate around tertiarization started, the growth of real output shares in services has been mainly attributed to shifts in private domestic consumption, which in turn has been claimed to be mainly sustained by a positive income effect, more than compensating for a negative price effect. However, the demand for services overall has been steadily growing, whereas average real income growth rates have been slightly declining from the mid1970s onwards (ten Raa and Schettkat 2001). As a consequence, ten Raa and Schettkat (2001) refer to what they call a more general 'change in demand conditions', which is claimed to dominate over the pure income and price effects in driving the 'service paradox'.

The 'service paradox', and particularly the black box of the 'change in demand conditions', is likely to be related to changes in the composition of intermediate demand. These latter might complement-and in some case dominate-the role of income- and price-led changes in final demand in accounting for structural change. The 'change in demand conditions'- namely the role of intermediate demand-is argued here to be overlooked in the Baumolian and post-Baumolian literature.

More generally, much effort has been devoted in the empirical literature to the identification of the sources of structural change, particularly in the contributions in the Input-Output (I-O) tradition, starting with Leontief (1951) and Leontief (1953). Within the I-O framework, and in the economic literature more generally (Pasinetti 1973, 1981), a full empirical account of structural economic change relies on the assessment of changes in sectoral interdependencies.

In line with this literature, in earlier work (Savona and Lorentz 2005) we decomposed sectoral output growth into the relative contribution of changes in intermediate coefficients and final domestic and foreign demand. We applied an I-O Structural Decomposition Analysis (SDA) technique ${ }^{1}$ to 13 selected macro-branches of the economy over the period from the end of the 1960s to the end of the 1990s for four Organisation for Economic Co-operation and Development (OECD) countries (Germany, Netherlands, UK and US).

The empirical evidence thereby identified can be summarized as follows:

- Real output growth since the beginning of the 1970s in most of the OECD countries has been positive for most of the service branches considered, and particularly for the Knowledge Intensive Business Services (KIBS). ${ }^{2}$ Further, this seems not to have crowded out the manufacturing branches, except in the UK and USA, between the end of the 1970s and the beginning of the 1980s.

\footnotetext{
${ }^{1}$ For an exhaustive review see Rose and Casler (1996).

${ }^{2}$ The term KIBS was first coined by Miles (1994) and variously reprised by among others Miles et al. (1995), Gallouj (2002). For a detailed list of the sectors considered as KIBS, see Table 1 in the Appendix.
} 
- The contribution of changes in intermediate coefficients to real output growth is much higher for service than manufacturing branches. The sources of structural change leading to growth in services are linked to both intermediate and final demand, whereas the output growth of manufacturing branches is mainly due to final (private and public) consumption. Unlike what has occurred in manufacturing branches, foreign demand has played a marginal role in the output growth of services, and this trend continued in the 1990s.

Our empirical findings are in line with those in recent work on the relative contribution of KIBS to aggregate performance, in terms of both output and productivity growth (van Ark et al. 2002; Peneder et al. 2003; Cainelli et al. 2006; Kox and Rubalcaba 2007). This supports our main conjecture that the role of changes in intermediate demand in driving the most dramatic changes in the sectoral structure of developed economies has been overlooked throughout the long debate on tertiarization, and particularly within the Baumolian literature.

The present work aims to reconcile the two-sided extended debate on the determinants of tertiarization, by considering 'Baumol's disease' as one possible-and time-specific - scenario, among others. To do so, we start from the 'service paradox' and the empirical stylized fact identified above, and account for the main sources of structural change of the economy by considering the role of technological change and changes in intermediate demand. To achieve this, we develop a formal model of economic growth with evolutionary micro-founded structural change.

The model developed is in line with attempts to embrace, within a unifying framework, both neo-Schumpeterian ${ }^{3}$ and Keynesian lines of thought in explaining economic growth (Verspagen 1993, 2002, 2004; Fagerberg 1994; Montobbio 2002).

The model extends that proposed in Llerena and Lorentz (2004) by providing an evolutionary micro-foundation for structural change in the economy. First, we provide a micro-foundation for the Kaldorian Cumulative Causation mechanism (Kaldor 1957, 1966). ${ }^{4}$ Second, we account for (demand-related) macro-constraints as affecting the micro-behavior of firms when adopting

\footnotetext{
${ }^{3}$ The importance of technical change for growth and competitiveness of firms, sectors and countries, emphasized by Schumpeter (1934) has been reprised within the neo-Schumpeterian stream of literature, starting from the seminal contribution by Nelson and Winter (1982) (See also, among others, Dosi et al. 1988; Chiaromonte and Dosi 1993; Silverberg and Verspagen 2005). This stream of literature is characterized by an almost exclusive focus on the nature and economic effects of technology adoption and diffusion, and neglects both the role of the demand-side determinants of firms' strategic behavior and the consequences of macro-level demand constraints. ${ }^{4}$ Interestingly, both Verspagen (1993), on the one hand, and Llerena and Lorentz (2004), on the other, re-consider Kaldor's Cumulative Causation mechanism. The former does so by introducing explicit 'evolutionary' selection processes within a cumulative causation framework, the latter by providing a micro-foundation of the process of emergence and diffusion of technologies. We refer the reader to both these contributions for a more detailed discussion of the use of the Kaldorian Cumulative Causation within the neo-Schumpeterian models.
} 
technology. Further, we account for the mechanisms transmitting the effects of micro-behavior on aggregate growth, via changes in the intermediate linkages.

The remainder of the paper is organized as follows. Section 2 develops a model of economic growth with evolutionary micro-founded structural change. In Section 3 we explain the methodology employed to simulate the model (Section 3.1); we identify three simulation scenarios (Section 3.2) and finally discuss the simulation results, the coherence between the empirical evidence found for the case of Germany and the simulated results (Section 3.3). Finally, Section 4 summarizes the main findings, draws some conclusions and proposes directions for future research.

\section{A model of evolutionary micro-founded structural change}

\subsection{The macro-economic framework}

Drawing on an I-O framework (Leontief 1951), we decompose the sectoral output $\left(Y_{j, t}\right)$ into three components: intermediate consumption $\left(I_{j, t}\right)$, final domestic consumption $\left(C_{j, t}\right)$ and (net) foreign final consumption $\left(X_{j, t}-M_{j, t}\right)$. The aggregate output is therefore a function of the sectoral structure of the economy, which in turn is determined by the intermediate and final components of demand.

$$
\left(\begin{array}{c}
Y_{1, t} \\
\vdots \\
Y_{j, t} \\
\vdots \\
Y_{J, t}
\end{array}\right)=\left(\begin{array}{c}
I_{1, t} \\
\vdots \\
I_{j, t} \\
\vdots \\
I_{J, t}
\end{array}\right)+\left(\begin{array}{c}
C_{1, t} \\
\vdots \\
C_{j, t} \\
\vdots \\
C_{J, t}
\end{array}\right)+\left(\begin{array}{c}
X_{1, t} \\
\vdots \\
X_{j, t} \\
\vdots \\
X_{J, t}
\end{array}\right)-\left(\begin{array}{c}
M_{1, t} \\
\vdots \\
M_{j, t} \\
\vdots \\
M_{J, t}
\end{array}\right)
$$

Intermediate consumption for sector $j$ is defined as the sum of the firms' demand of sector $j$ product and is characterised as follows:

$$
I_{j, t}=\sum_{k=1}^{J} Y_{j, k, t}^{D}=\sum_{k=1}^{J} a_{j, k, t} Y_{k, t}
$$

where $Y_{j, k, t}^{D}$ represents the demand for sector $j$ products by the sector $k ; Y_{k, t}$ represents the level of production in sector $k$, and the coefficients $a_{j, k, t}$ are computed as follows:

$$
a_{j, k, t}=\sum_{i} z_{k, i, t} a_{j, k, i, t}
$$

where $z_{k, i, t}$ represents the market share of firm $i$ belonging to sector $k$; market shares are defined by Eq. 18 and $a_{j, k, i, t}$ represents the coefficient of intermediate consumption of firm $i$ (belonging to sector $k$ ) for sector $j$ products. 
The vector $I_{t}$ of intermediate consumption can therefore be represented as follows:

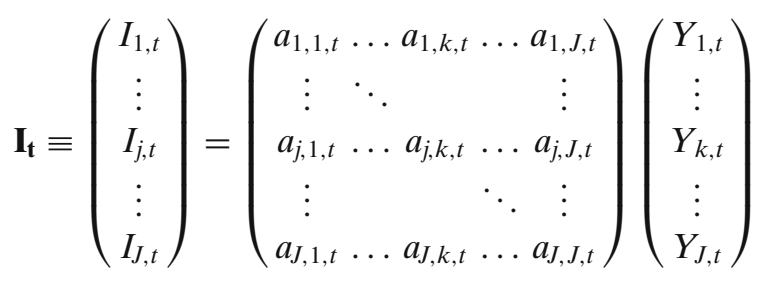

Final consumption is a function of the aggregate real income level. Final consumption for sector $j\left(C_{j, t}\right)$ is a share $c_{j, t}$ of the aggregate real income level:

$$
C_{j, t}=c_{j, t} Y_{t}
$$

Real income is linked to real GDP and is given by the sum of sectoral nominal output deflated by the aggregate price index. The level of consumption devoted to each sector $j$ can therefore be expressed as follows:

$$
C_{j, t}=c_{j, t} \sum_{k=1}^{J} \frac{p_{k, t}}{\bar{p}_{t-1}} Y_{k, t}
$$

where $\bar{p}_{t-1}$ represents the aggregate price index. ${ }^{5}$ The vector $C_{t}$ of final consumption is computed as follows:

$$
\mathbf{C}_{\mathbf{t}} \equiv\left(\begin{array}{c}
C_{1, t} \\
\vdots \\
C_{j, t} \\
\vdots \\
C_{J, t}
\end{array}\right)=\left(\begin{array}{cccccc}
c_{1, t} \frac{p_{1, t}}{\bar{p}_{t-1}} & \ldots & c_{1, t} \frac{p_{k, t}}{\bar{p}_{t-1}} \ldots & c_{1, t} \frac{p_{J, t}}{\bar{p}_{t-1}} \\
\vdots & \ddots & & & \vdots \\
c_{j, t} \frac{p_{1, t}}{\bar{p}_{t-1}} & \ldots & c_{j, t} \frac{p_{k, t}}{\bar{p}_{t-1}} & \ldots & c_{j, t} \\
\vdots & & & \ddots & \vdots \\
c_{J, t} & \\
c_{J, t} \frac{p_{1, t}}{\bar{p}_{t-1}} & \ldots & c_{J, t} \frac{p_{k, t}}{\bar{p}_{t-1}} & \ldots & c_{J, t} \\
\bar{p}_{J-1}
\end{array}\right)\left(\begin{array}{c}
Y_{1, t} \\
\vdots \\
Y_{k, t} \\
\vdots \\
Y_{J, t}
\end{array}\right)
$$

For each sector the level of imports $\left(M_{j, t}\right)$ corresponds to a share $m_{j, t}$ of the total domestic demand of the sector $\left(I_{j, t}+C_{j, t}\right)$. This share can be a proxy for the international competitiveness of the economy. Sectoral net exports are defined as follows:

$$
X_{j, t}-M_{j, t}=X_{j, t}-m_{j, t}\left(I_{j, t}+C_{j, t}\right)
$$

${ }^{5}$ The price index is computed as:

$$
\bar{p}_{t}=\sum_{k=1}^{J} p_{k, t} \frac{p_{k, t} Y_{k, t}}{\sum p_{k, t} Y_{k, t}}
$$


Using Eqs. 4 and 6 we define the vector of net exports $\left(X_{t}-M t\right)$ as follows:

$$
\begin{aligned}
\mathbf{X}_{\mathbf{t}}-\mathbf{M}_{\mathbf{t}} \equiv & \left(\begin{array}{c}
X_{1, t} \\
\vdots \\
X_{J, t}
\end{array}\right)-\left(\begin{array}{ccc}
m_{1, t}\left(a_{1,1, t}+c_{1, t} \frac{p_{1, t}}{\bar{p}_{t-1}}\right) & \ldots & m_{1, t}\left(a_{1, J, t}+c_{1, t} \frac{p_{J, t}}{\bar{p}_{t-1}}\right) \\
\vdots & \ddots & \vdots \\
m_{J, t}\left(a_{J, 1, t}+c_{J, t} \frac{p_{1, t}}{\bar{p}_{t-1}}\right) & \ldots & m_{J, t}\left(a_{J, J, t}+c_{1, t} \frac{p_{J, t}}{\bar{p}_{t-1}}\right)
\end{array}\right) \\
& \times\left(\begin{array}{c}
Y_{1, t} \\
\vdots \\
Y_{J, t}
\end{array}\right)
\end{aligned}
$$

By substituting Eqs. 4, 6 and 7 in Eq. 1, we obtain the following expression for the vector of sectoral demand:

$$
\left(\begin{array}{c}
Y_{1, t} \\
\vdots \\
Y_{j, t} \\
\vdots \\
Y_{J, t}
\end{array}\right)=\left(\begin{array}{ccccc}
\alpha_{1,1, t} & \ldots & \alpha_{1, k, t} & \ldots & \alpha_{1, J, t} \\
\vdots & \ddots & & \vdots \\
\alpha_{k, 1, t} & \ldots & \alpha_{j, k, t} & \ldots & \alpha_{k, J, t} \\
\vdots & & & \ddots & \vdots \\
\alpha_{J, 1, t} & \ldots & \alpha_{1, k, t} & \ldots & \alpha_{J, J, t}
\end{array}\right)\left(\begin{array}{c}
Y_{1, t} \\
\vdots \\
Y_{k, t} \\
\vdots \\
Y_{J, t}
\end{array}\right)+\left(\begin{array}{c}
X_{1, t} \\
\vdots \\
X_{j, t} \\
\vdots \\
X_{J, t}
\end{array}\right)
$$

with

$$
\alpha_{j, k, t}=\left(1-m_{j, t}\right)\left(a_{j, k, t}+c_{j, t} \frac{p_{k, t}}{\bar{p}_{t-1}}\right)
$$

We obtain the reduced form of our model from this last equation, assuming the short-run macroeconomic identity holds:

$$
\left(\begin{array}{c}
Y_{1, t} \\
\vdots \\
Y_{j, t} \\
\vdots \\
Y_{J, t}
\end{array}\right)=\left(\begin{array}{ccccc}
1-\alpha_{1,1, t} & \ldots & -\alpha_{1, k, t} & \ldots & -\alpha_{1, J, t} \\
\vdots & \ddots & & & \vdots \\
-\alpha_{k, 1, t} & \ldots & 1-\alpha_{j, k, t} & \ldots & -\alpha_{k, J, t} \\
\vdots & & \ddots & \vdots \\
-\alpha_{J, 1, t} & \ldots & -\alpha_{1, k, t} & \ldots & 1-\alpha_{J, J, t}
\end{array}\right)^{-1}\left(\begin{array}{c}
X_{1, t} \\
\vdots \\
X_{k, t} \\
\vdots \\
X_{J, t}
\end{array}\right)
$$

The vector of sectoral demand, therefore, is obtained as a function of the demand parameters only, given in the short-run (but evolving over time), and of exports. The latter are assumed to be exogenously defined.

\subsection{The micro-behaviors}

At the micro-level firm output is determined by its share of sectoral demand. The production technology of a firm consists of a combination of products from all sectors (including the one to which the firm belongs) and labor, as defined by the production function (Eq. 10). 
The labor productivity dynamics for each firm are assumed to follow a Kaldor-Verdoorn Law (Verdoorn 1949; Kaldor 1966). A technological shock is represented by changes in firms' labor productivity, on the basis of a KaldorVerdoorn mechanism and, simultaneously, by changes in the structure of the intermediate coefficients.

A firm $i$ active in sector $k$ is defined by the following production function:

$$
Y_{k, i, t}=\min \left(\frac{1}{a_{1, k, i, t}} Y_{1, k, i, t}^{D}, \ldots, \frac{1}{a_{j, k, i, t}} Y_{k, k, i, t}^{D}, \ldots, \frac{1}{a_{J, k, i, t}} Y_{J, k, i, t}^{D}, A_{k, i, t} L_{k, i, t}\right)
$$

The level of production of firm $i$ in sector $k$ is defined as a share $z_{k, i, t}$ of sector $k$ 's demand:

$$
Y_{k, i, t}=z_{k, i, t} Y_{k, t}
$$

The level of demand from firm $i$ for sector $j$ products is therefore defined as follows:

$$
Y_{j, k, i, t}^{D}=a_{j, k, i, t} Y_{k, i, t}
$$

The demand for labor expressed by firm $i$ is defined as follows:

$$
L_{k, i, t}=\frac{Y_{k, i, t}}{A_{k, i, t}}
$$

$A_{k, i, t}$ represents the labor productivity of firm $i$.

Technical change at the level of the firm consists of changes in labor productivity (Eq. 14), and by changes in the coefficient of intermediate demand $\left(a_{j, k, i, t}\right)$.

Labor productivity dynamics are represented as follows:

$$
\frac{\Delta A_{k, i, t}}{A_{k, i, t-1}}=\beta_{k}+\lambda_{k} \frac{\Delta Y_{k, i, t}}{Y_{k, i, t-1}}
$$

The changes in intermediate demand coefficients are assumed to be stochastic. Changes in intermediate coefficients are formally represented by the following algorithm:

1. Firms draw a number from a Uniform distribution on $[0 ; 1]$.

2. If this number is contained in the interval $[0 ; \sigma]$, a technological shock occurs. $\sigma$ is the fixed probability of a technological shock occurring.

3. If a technological shock occurs, every coefficient changes according to the following procedure:

$$
\begin{array}{r}
a_{j, k, i, t}^{\prime}=a_{j, k, i, t-1}+\epsilon_{j, k, i, t} \\
\epsilon_{j, k, i, t} \sim N(0 ; \rho)
\end{array}
$$

where $\rho$ is a given. 
The new set of coefficients $\left(a_{1, k, i, t}^{\prime}, \ldots, a_{j, k, i, t}^{\prime}, \ldots, a_{J, k, i, t}^{\prime}\right)$ is introduced in the production function if the potential unitary cost is lower then the actual unitary $\operatorname{cost}\left(\kappa_{k, i, t}\right)$ :

$$
\left(a_{1, k, i, t+1}, \ldots, a_{J, k, i, t+1}\right)=\left\{\begin{array}{l}
\left(a_{1, k, i, t}^{\prime}, \ldots, a_{j, k, i, t}^{\prime}, \ldots, a_{J, k, i, t}^{\prime}\right) \text { If } \sum_{j=1}^{J} a_{j, k, i, t}^{\prime} p_{j, t}<\kappa_{k, i, t} \\
\left(a_{1, k, i, t}, \ldots, a_{j, k, i, t}, \ldots, a_{J, k, i, t}\right) \text { Otherwise }
\end{array}\right.
$$

The market share of firm $i$ is defined by a replicator dynamic, as follows:

$$
z_{k, i, t}=z_{k, i, t-1}\left(1+\phi\left(\frac{E_{k, i, t}}{E_{k, t}}-1\right)\right)
$$

where $E_{k, i, t}$ and $E_{k, t}$ respectively, represent the level of competitiveness of firm $i$ and the average competitiveness in sector $k$. Each firm's competitiveness level is defined as the inverse of the firm's price level:

$$
E_{k, i, t}=\frac{1}{p_{k, i, t}}
$$

Firms set prices, applying a mark-up $\left(\mu_{k, i}\right)$ on their unitary production costs $\left(\kappa_{k, i, t}\right)$. These latter are defined as:

$$
\kappa_{k, i, t}=\sum_{j=1}^{J} a_{j, k, i, t} p_{j, t}+\frac{w_{k, t}}{A_{k, i, t}}
$$

where $p_{j, t}$ represents the average price in sector $j$ :

$$
p_{j, t}=\sum_{i} z_{j, i, t} p_{j, i, t}
$$

and $w_{k, t}$ is the wage rate applied in sector $k$ at time $t$. Firms set prices as follows:

$$
p_{k, i, t}=1+\mu_{k, i}\left(\sum_{j=1}^{J} a_{j, k, i, t} p_{j, t}+\frac{w_{k, t}}{A_{k, i, t}}\right)
$$

Wages are set at sectoral level. For a given sector $k$, the wage dynamic is correlated with sector $k$ productivity ${ }^{6}$ growth rate $\left(\frac{\Delta A_{k, t}}{A_{k, t-1}}\right)$ as well as with the

${ }^{6}$ With

$$
A_{t}=\frac{Y_{t}}{L_{t}} \text { and } A_{k, t}=\frac{Y_{k, t}}{L_{k, t}} .
$$


aggregate productivity growth rate $\left(\frac{\Delta A_{t}}{A_{t-1}}\right)$. The effect of these two variables on wage dynamics is weighted by the parameter $v \in[0 ; 1]$, such that :

- When $v=1$, the wage dynamics in each sector depend on the macro-level productivity growth rate (i.e. as a centralized wage negotiation system);

- When $v=0$, the wage dynamics in each sector depend on the sector-level productivity growth rate (i.e. as a sectoral wage negotiation system);

The wage dynamic of sector $k$ is defined as:

$$
\frac{\Delta w_{k, t}}{w_{k, t-1}}=v \frac{\Delta A_{t}}{A_{t-1}}+(1-v) \frac{\Delta A_{k, t}}{A_{k, t-1}}
$$

Note that wage negotiations occur during the period $t$ and the resulting wage level is applied by firms at period $t+1$. Wage dynamics in our model act as a second macro-constraint on firms, as they directly affect firm competitiveness. Firms lose competitiveness if their productivity growth rates are slower than the average.

Moreover, $v \neq 0$, wage dynamics generate a selection process among sectors. If the sectoral average productivity grows at a slower rate than the average aggregate productivity growth rate, this sector loses competitiveness, due to the wage dynamics mechanism. The amplitude of this effect is a function of the value of the parameter $v$.

A firm exits the market if its market share is below $\bar{z}$. In this case, it is immediately replaced by a firm whose characteristics correspond to the average value of the sectoral characteristics.

The dynamic functioning of the model is based on the following mechanisms, across different levels of analysis:

1. An (exogenous) technological shock translates, at the firm level, into lower costs and prices. These latter increase firms' market shares. An increase in market shares leads to a growth in firms' output. In turn, the KaldorVerdoorn mechanism ensures that output growth translates into positive labor productivity dynamics, further lowering costs and prices and further increasing market shares.

2. At the sectoral level, the micro-dynamics affect the structure of intermediate demand. This in turn feeds back into the growth of firms (and their potential productivity growth), by constraining sectoral demand growth. This ensures the presence of meso-to-micro feedback mechanisms.

3. At the macro-level, growth is a function of (i) the single firm's adoption of technological shocks; (ii) the meso-level diffusion of these shocks and changes in intermediate demand; (iii) changes in the structure of final consumption, in relative prices, and in the employment structure induced by the diffusion of these shocks at the macro-level. In turn, aggregate growth constrains sectoral growth and, consequently, firms' growth potential and labor productivity. Respectively, these changes exemplify macro-to-meso and macro-to-micro feedback mechanisms. 
Structural change is the outcome of the co-evolution of these three levels of dynamic mechanisms and the feedback occurring between them.

\section{Simulation results}

\subsection{Simulation procedure}

We conducted numerical simulations on the model developed in Section 2. The simulation setting is summarized as follows:

- the country specification contains 13 sectors, corresponding to the 13 sectors in the I-O SDA carried out in Savona and Lorentz (2005) and reported for convenience in Table 1 in the Appendix;

- each of the sectors includes 20 firms;

- the results presented are the average outcome of a minimum of 50 replications of the simulation setting;

- each simulation runs over 500 steps.

In order to reduce the spectrum of parameters to be analyzed, we set the initial structure of the economy on the basis of the data used in Savona and Lorentz (2005), focusing on the German case. The simulations are carried out on the basis of the actual OECD I-O tables (1978-1995) and OECD STAN (1970-1999), at the first time-step, for the following variables and parameters:

- Sectoral intermediate I-O coefficients $\left(a_{j, k, t}\right)$. The intermediate coefficients are drawn from the German I-O table for 1978 (Table 2 in the Appendix).

- Sectoral exports $\left(X_{j, t}\right)$. These figures are drawn from the I-O table for Germany 1978 (Table 3 in the Appendix).

- Sectoral shares of final consumption $\left(c_{j, t}\right)$. These are computed as the ratio of sector consumption and total consumption using the 1978 German I-O table (Table 3 in the Appendix).

- Sectoral shares of import $\left(m_{j, t}\right)$. These are computed as the ratio of sectoral foreign demand and total demand (final and intermediate), once again using the 1978 German I-O table (Table 3 in the Appendix).

- Sectoral Kaldor-Verdoorn parameters $\left(\beta_{j}\right.$ and $\left.\lambda_{j}\right)$. These figures are estimated using the OECD STAN (1970-1999) data (Table $3^{7}$ ).

We identify three stylized scenarios based on different parameter settings, and analyze the occurrence of structural change on the basis of each of these scenarios in the case of the simulation specification illustrated above. The scenarios are detailed in Section 3.2. It is useful to bear in mind that the objective is not to carry out a proper calibration exercise, as we do not aim

\footnotetext{
${ }^{7}$ The Kaldor-Verdoorn elasticities are estimated over the same time-span (1970-1999) covered by the OECD I-O Tables. We chose to gain in coherence rather than in the actuality of the data with respect to the hypotheses formulated in Section 1, which refer to the time-span in the I-O tables of 1978-1995.
} 
to reproduce the trend observed in the data. Rather, we want to investigate whether the results that emerge from the various simulation scenarios are plausible with respect to the empirical evidence in Section 1.

We quantify the occurrence of structural change in terms of two different dimensions:

1. the degree of concentration, in income (nominal product), real output and employment, measured using an inverse Herfindahl index. This index is intended to measure the unevenness of labor and resource allocations among sectors, as well as changes in the latter;

2. the sectoral composition of the economy, in terms of real output and employment. This dimension allows us to analyze the nature of the changes in the structure of the economy generated by the various scenarios.

\subsection{Simulation scenarios}

Three main scenarios driving structural change are identified, based on changes in intermediate demand. Each of these scenarios corresponds to a specific setting for a number of key parameters. They are described as follows.

1. The "Baumol's disease" scenario: The structural changes in both the employment and output composition of the economy are driven by the productivity growth differentials among sectors. This scenario emerges as a result of cross-sector differences in the Kaldor-Verdoorn parameters, holding final and intermediate demand constant. These differences lead to higher shares of employment in the sectors with lowest productivity growth, and affect the structure of the economy through wage and price dynamics. Structural change based on this scenario emerges if productivity growth differences are not perfectly absorbed by wages, i.e. when the wage setting is centralized. The parameters are set as follows:

(a) the changes in intermediate coefficients are neutralized $(\sigma=0)$;

(b) wages are centralized $(v=1)$;

(c) the selection mechanism occurs $(\phi=1)$;

(d) the structure of final demand remains constant (All $\left.c_{j, t}=c_{j}\right)$.

2. The "Schumpeterian" scenario: ${ }^{8}$ Structural change is exclusively driven by firms' reactions to technological shocks. The differences in productivity growth rates are neutralized by decentralized wages. The diffusion of the shocks to the economy relies only on the selection mechanism occurring at sectoral level. Structural change is therefore due only to the characteristics

\footnotetext{
${ }^{8}$ We refer here to the Neo-Schumpeterian models considered in Section 1, which consider the technological changes occurring at the firm level as being driven by stochastic processes.
} 
of the stochastic processes underlying the changes in the intermediate coefficients and the selection mechanism. The parameters are set as follows:

(a) the changes in intermediate coefficient occur $(\sigma \neq 0)$;

(b) wages neutralize the differences in sectoral productivity growth rate $(v=0)$

(c) the selection mechanism occurs $(\phi=1)$;

(d) the structure of final demand remains constant (All $c_{j, t}=c_{j}$ );

3. The "Cost reduction" scenario: Structural change is triggered by both the reaction to technological shocks by firms and the differences in productivity growth rates among sectors. Centralized wage-setting allows these differences to affect both wages and prices and, therefore, production costs. Technological shocks are adopted when they affect production costs. Adoption is therefore biased towards the most productive sectors. In combination with the selection mechanisms, this bias should amplify the effects on structural change as emerge in the "Baumol's disease" scenario. In this case the parameters are set as follows:

(a) the changes in intermediate coefficient occur $(\sigma \neq 0)$;

(b) wages are centralized $(v=1)$;

(c) the selection mechanisms occur $(\phi=1)$;

(d) the structure of final demand remains constant (All $\left.c_{j, t}=c_{j}\right)$.

The scenarios rely on a limited number of parameter changes. Modifying the values for $\sigma$ and $v$ allows us to consider three different sets of causalities leading to changes in the structure of intermediate demand, i.e. supply- and intermediate demand-led structural changes.

\subsection{The case of Germany}

The empirical evidence for Germany, as per Savona and Lorentz (2005), shows an increase in the degree of concentration of output between 1978 and 1995. In other words, aggregate output has been growing, but in a small number of sectors.

Figures 1 to 3, respectively, present the degree of concentration for income, employment and real output. The figures were obtained for various specifications of the parameters $\sigma$ and $v$, in such a way that they emerge as the effects of the dynamics consequent on the three different scenarios. In particular:

- keeping $\sigma$ null and moving along the y-axis corresponds to the emergence of a "Baumol's disease" type of dynamics;

- keeping $v$ null and moving along the $\mathrm{x}$-axis corresponds to a "Schumpeterian" type of structural change dynamics;

- modifying simultaneously $v$ and $\sigma$ generates a "Cost reduction" type of structural change.

As illustrated by Fig. 1, in the two extreme cases, the "Baumol's disease" and the "Schumpeterian", the dynamics lead to lower degrees of concentration 
Fig. 1 Income sectoral concentration (Inverse Herfindahl index)

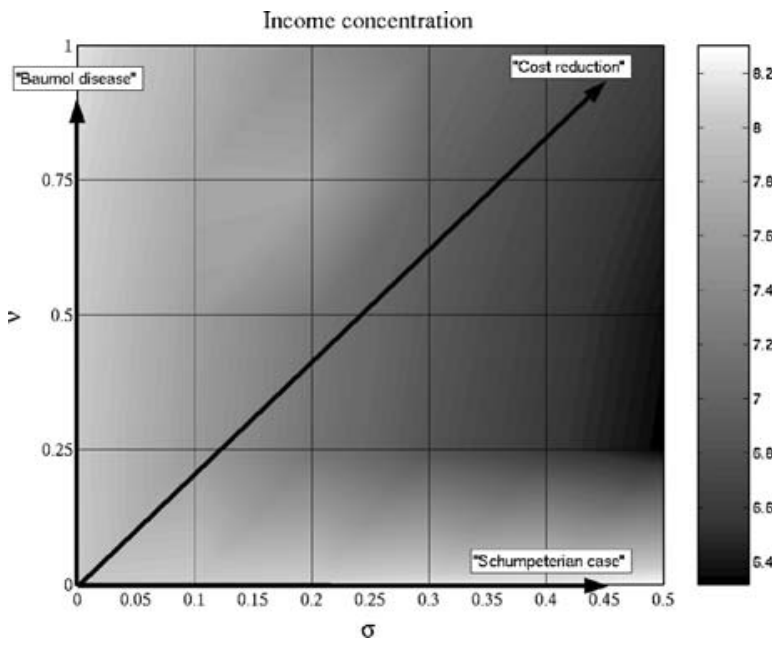

in income with respect to the "Cost Reduction" or intermediate cases. A similar pattern emerges when considering the concentration in employment (see Fig. 2).

Figure 3 presents the concentration levels in terms of output, measured for the various specifications of parameters $v$ and $\sigma$. A dramatic difference is evident with respect to income and employment. As the wage dynamics tend to be more centralized, when keeping the probability of technological shocks to zero, the output concentration becomes higher. Economic activity is therefore more concentrated in the "Baumol's disease" and the "Cost reduction" scenarios, while the dynamics considered in the "Schumpeterian" scenario lead to a lower level of concentration (higher dispersion).

In the course of the simulations of the "Baumol's disease" case, the output tends, on average, to be concentrated in a small number of sectors. This

Fig. 2 Employment concentration (Inverse Herfindahl index)

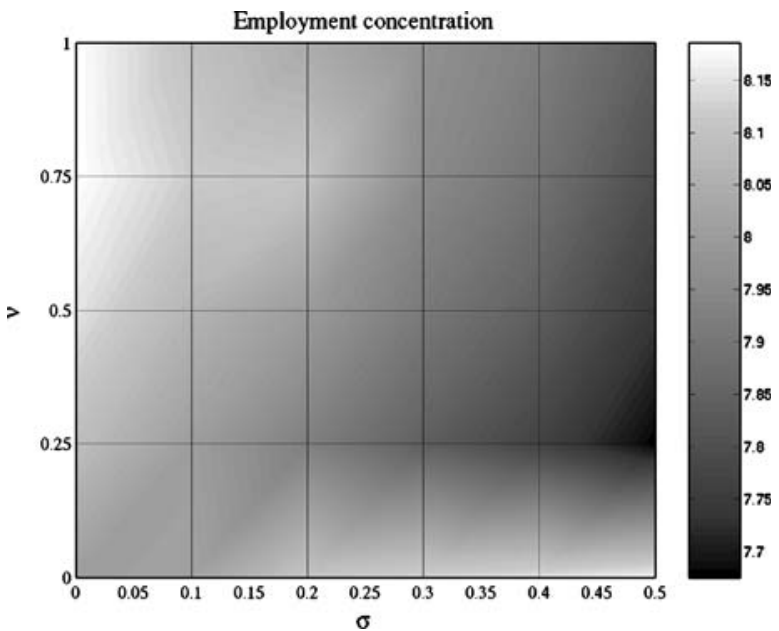


Fig. 3 Real output concentration (Inverse Herfindahl index)

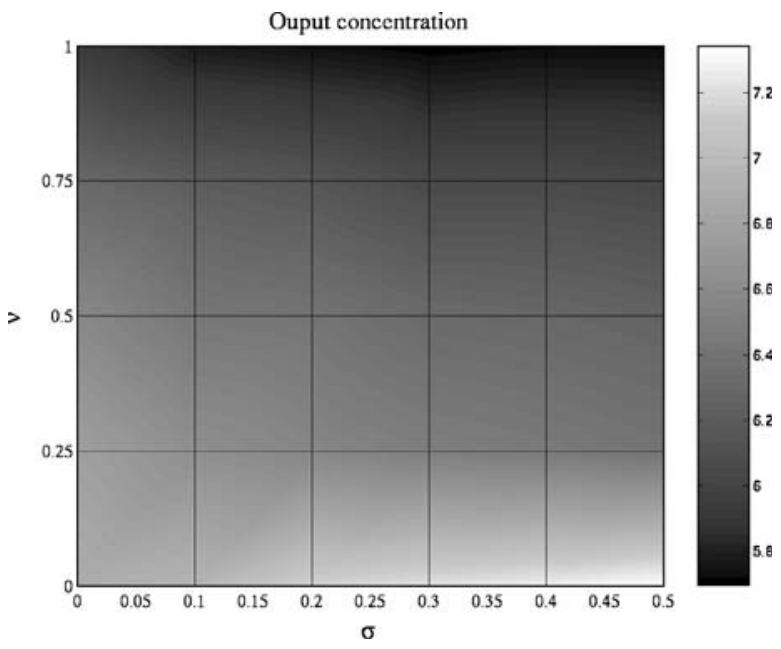

tendency is amplified as wages tend to be more centralized. Similar patterns emerge for the "Cost reduction" case. In the "Schumpeterian" scenario, however, the structural changes generated by the simulations lead to lower concentration, or higher value of the inverse Herfindahl index.

The differences in the outcomes of the three scenarios are less obvious for employment. In all cases, in the course of the simulations, employment is concentrated in a smaller number of sectors. The employment dynamics are mainly driven by the productivity dynamics, which explains the similarities in these patterns. Small differences can, however, be observed: in the "Schumpeterian" case, the more frequent technological shocks slightly slow down the employment concentration. In the case of the "Baumol's disease" scenario, and the "Cost reduction" scenario, a higher degree of wage centralization seems to slow down slightly the concentration process.

These findings can be explained as follows. In the "Baumol's disease" case, structural change is driven only by the differences in productivity dynamics across sectors. As wages are centralized, these productivity differences directly affect the demand structure, via the relative prices and the employment structure. Sectors with higher (than average) productivity growth experience a decrease in prices over time and, therefore, an increase in market shares. This explains the growth in the degree of concentration of real output. The high productivity growth sectors increase their levels and shares of output, reducing their costs and prices. The low productivity growth sectors reduce their levels of output as they experience an increase in costs and prices. These two effects compensate for one another, explaining the low degree of concentration in the income structure. Similarly the losses/gains, in output are partially compensated for by the higher/lower, gains in labor productivity, implying a reduction/increase, in the sectoral shares of total employment. This would also account for the lower degree of concentration in the employment structure. 
In the "Schumpeterian" case, wages are decentralized and therefore absorb completely the differences in productivity dynamics. The only source of structural change are the technological shocks occurring at the micro-level, which change the technological coefficients. The more frequent the shocks, the more frequent the changes in the structure of intermediate demand. However, the shocks follow similar patterns among sectors. As a consequence, technological shocks tend to reduce the sectoral differences in intermediate demand. Therefore, the more frequent the shocks, the lower the degree of concentration in output. As wages absorb the changes in labor productivity, price dynamics follow the changes in the technological coefficients. At the meso-level, this implies less concentration in output and in the income structure. The employment structure of the economy is a direct consequence of the differences in productivity dynamics among sectors, though this effect is slowed by the technological shocks.

In the "Cost reduction" scenario, structural change is simultaneously due to the differences in the productivity dynamics among sectors and to the technological shocks. In this case, as technological shocks diffuse among the sectors and in the economy, they tend to amplify the sectoral heterogeneity in intermediate demand due to the differences in productivity growth rates. The shocks are absorbed at the micro and meso levels through selection mechanisms, only if these reduce the production costs. The absorbed shocks are those favoring the most productive sectors. Hence, the productivity growth differences affect demand, via relative prices, but also through the cost reduction linked to the adoption of technological shocks. In line with the KaldorVerdoorn law, the sectors with higher demand growth experience higher productivity growth. The combination of these two mechanisms, therefore, reinforces the concentration dynamics in a small number of highly productive sectors.

Figures 4 to 9 present the evolution of the sectoral composition of the economy for each of the scenarios. This allows us to consider in more detail the nature of the structural changes occurring through the various scenarios.

In the "Baumol's disease" case (Fig. 4), except for the SOCIAL sector, all the service sectors, and especially KIBS and TRADE, decline. Manufacturing activities, on the other hand, have an increased role in the economy. The manufacturing sectors (especially MACHINERY), together with the SOCIAL sector, experience the highest productivity growth while, as expected, these sectors experience a drastic drop in employment shares (Fig. 5). KIBS and TRADE are the two sectors that experience the highest increase in employment shares. The "Baumol's disease" mechanism certainly explains the growth of employment in services. However, structural changes as generated in this scenario lead to a re-industrialization and a de-tertiarization of the economy in terms of output created. The mechanisms behind the "Baumol's disease" scenario favor high productivity manufacturing activities, yet they are unable to account for the empirical evidence for the case of KIBS.

Similarly, structural changes in the "Cost reduction" scenario favor manufacturing activities (Fig. 6). The changes in the output structure are ampli- 
Fig. 4 Sectoral composition in real output ("Baumol disease")

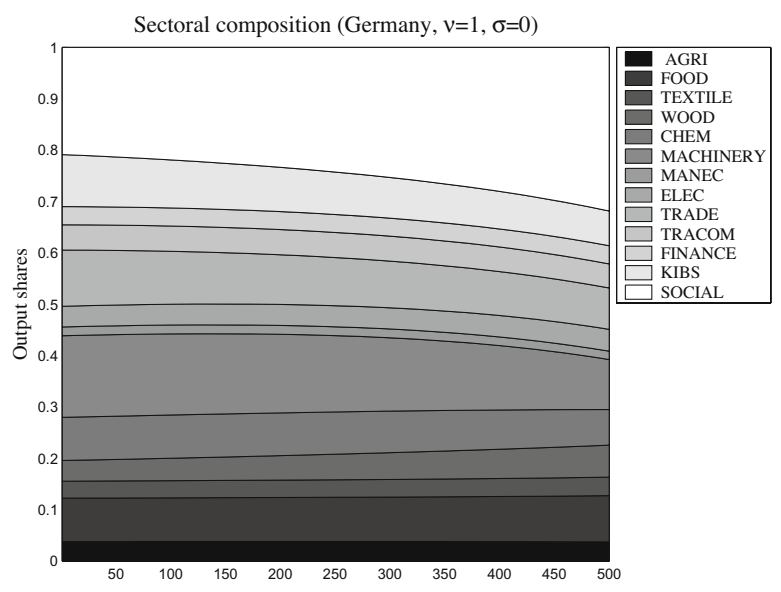

fied with respect to the "Baumol's disease" case. Again, the manufacturing branches benefit from the mechanisms underlying this scenario, due to the fact that these sectors are characterized by higher productivity growth rates. This result is directly linked to the fact that the dynamics implied in this scenario accelerate and amplify the effects triggered by productivity differences (as in the "Baumol disease" case) or by technological shocks.

In terms of employment, however, slight differences occur. For certain manufacturing activities (especially MACHINERY), the share of employment slightly increases (Fig. 7). The growth of output, therefore, over-compensates for the loss of employment potentially induced by the productivity dynamics.

In the "Schumpeterian" case, structural changes lead to a convergence in the output share of each sector (Fig. 8). This result is directly linked to the symmetry of the technological shocks among sectors. These latter follow the same distribution patterns across sectors.

Fig. 5 Employment sectoral composition ("Baumol disease")

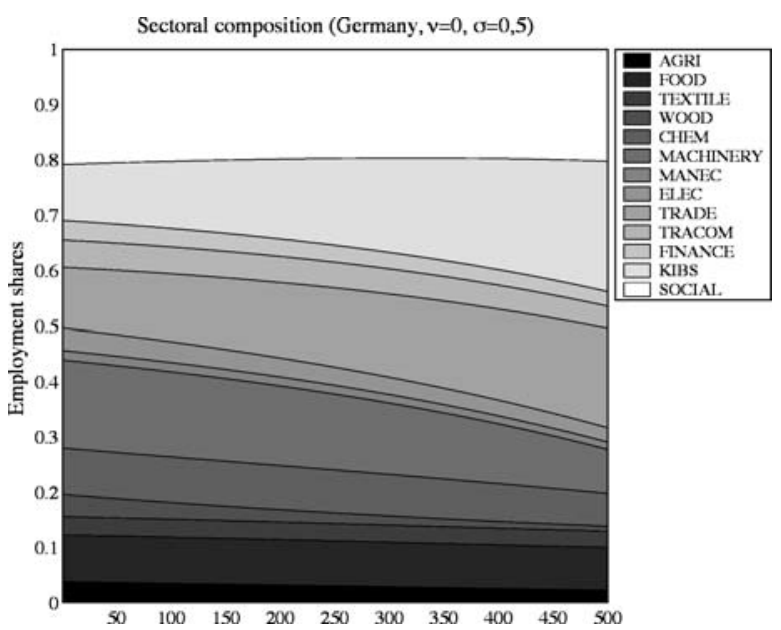


Fig. 6 Sectoral composition in real output ("Cost reduction")

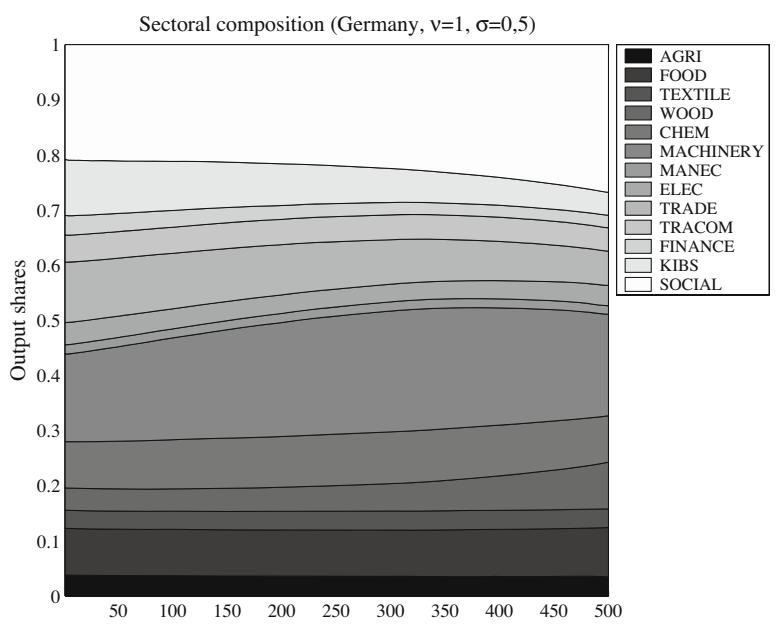

The structure of employment shows the same trend as that in the "Baumol's disease" case (Fig. 9). Employment is structured by the productivity differences, as in the above case. As wages are decentralized, the effect of the productivity differences is confined to the employment structure.

Figure 10 presents the evolution of the sectoral structure in Germany for the period 1978-1995. There is a clear tendency toward tertiarization with the rise of KIBS and SOCIAL shares and, more generally, a gain in importance of all the service sectors, accompanied by a relative decline in manufacturing activities.

Fig. 7 Employment sectoral composition ("Cost reduction")

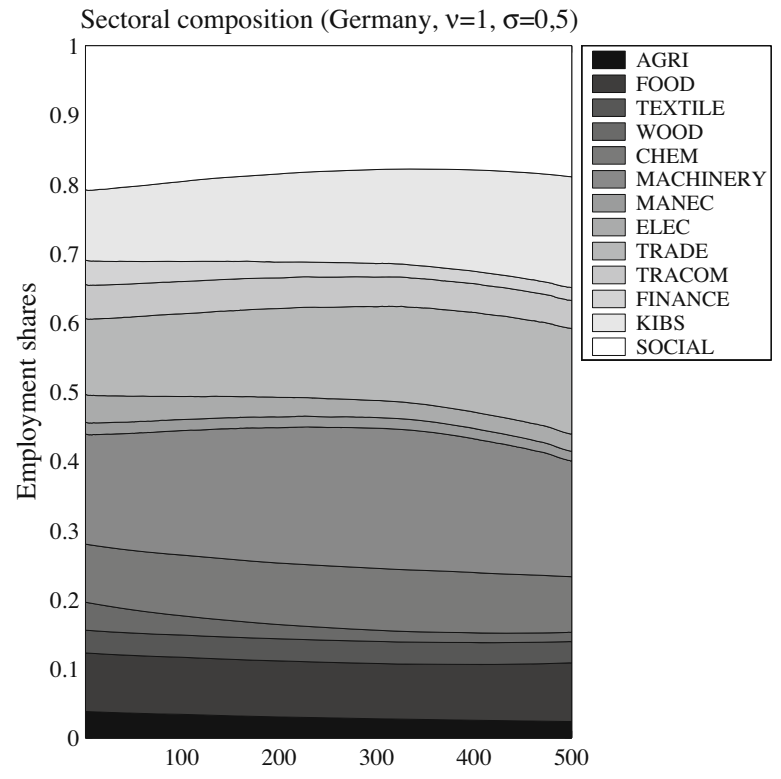


Fig. 8 Sectoral composition in real output ("Schumpeterian case")

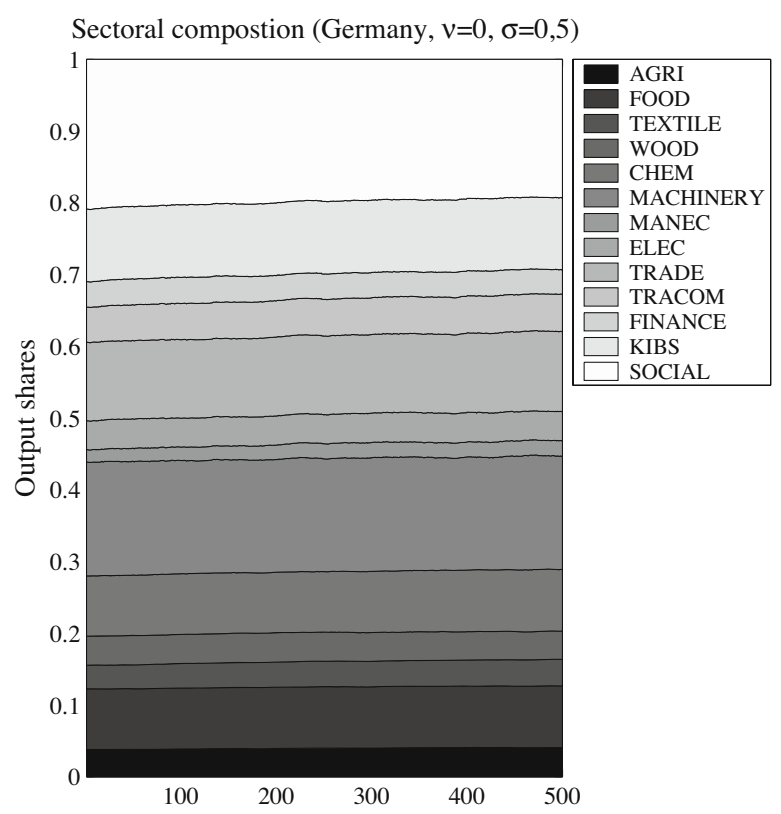

This structure is the opposite to the one generated by the "Baumol's disease" and the "Cost reduction" scenarios, which rely on the existence of productivity differences among sectors. The growth of services in Germany can hardly be completely imputed to productivity growth rate differentials. The simulated results for the various scenarios allow us to question seriously the "Baumol's disease" explanation, at least for the period considered.

Moreover, the growth of services in Germany seems to have been complementary rather than detrimental to the growth in manufacturing sectors.

Fig. 9 Employment sectoral composition ("Schumpeterian case")

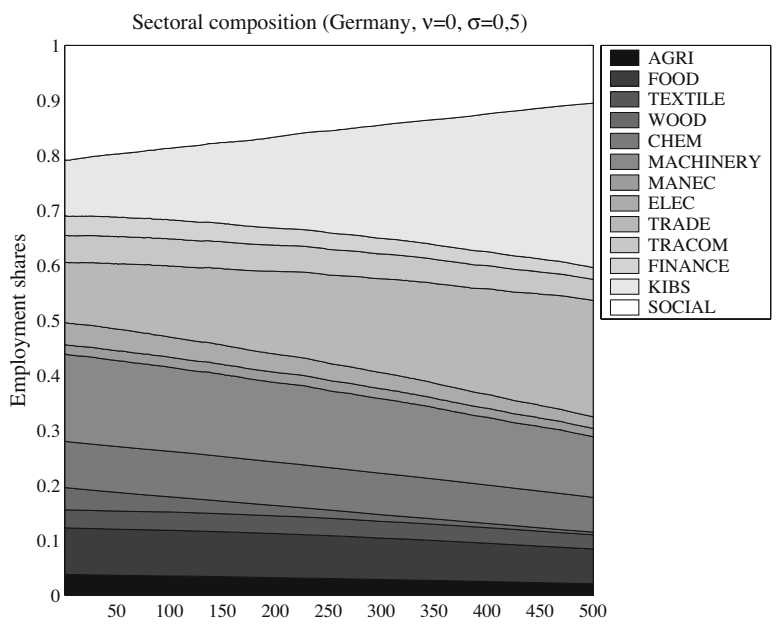


Fig. 10 Sectorial composition in real output (Germany 1978-1995)

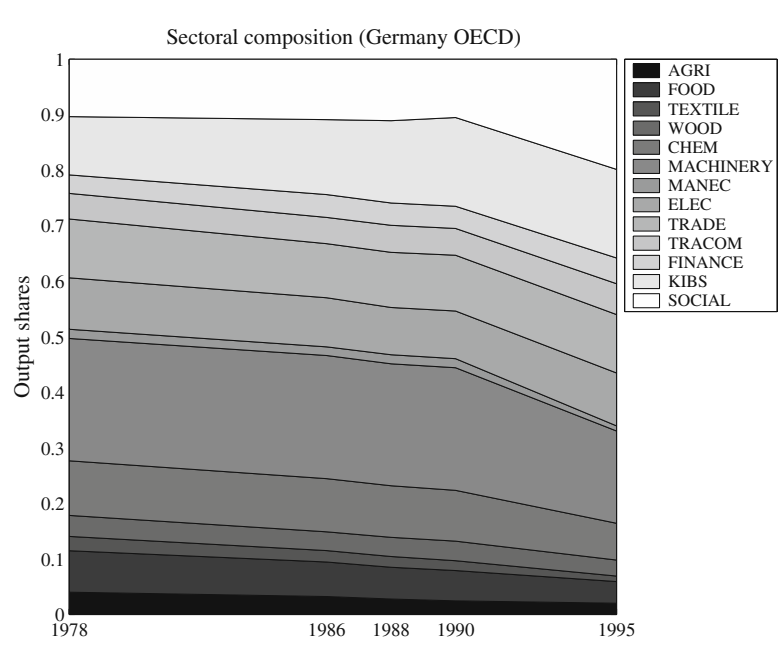

Tertiarization processes in Germany have been driven by the combination of highly productive manufacturing sectors and asymmetric technological shocks. These shocks have favored the expansion of services following an increase in the inter-sectoral division of labor and an increase in intermediate demand for service activities.

\section{Final remarks}

The paper aimed to add to the on-going debate on the determinants of structural changes to the economy, particularly those leading to the growth of services. In the present work, we have built upon the empirical evidence found in Savona and Lorentz (2005) and summarized in Section 1. Our conjecture is that the determinants of structural change, and particularly the growth of services in the advanced countries over the last few decades, imply the copresence of (and most likely a virtuous circle between) a sustained growth in patterns of final demand and radical changes in the sectoral division of labor.

A growth model with evolutionary micro-founded structural change was developed in Section 2. The model was simulated on the basis of three different scenarios, accounting for both intermediate demand and technological determinants of structural change. The scenarios were identified both along the main lines around which the debate over tertiarization has revolved over time, and on the empirical evidence found in previous work and recalled in Section 1.

The simulation results based on the actual German data allow us to conclude that the structural changes that occurred in the case of Germany cannot only be due to inter-sectoral differences in productivity growth. In other words, and in line with the empirical evidence, the "Baumol's disease" case is not able to account for the actual (and most recent) patterns of tertiarization that have 
occurred in Germany. Rather, it is the intertwined effect of changes in the intermediate demand and technological shocks that has been operating.

However, more a refined account of the nature and effects of technological shocks at the micro-level should be considered. The model is based on the hypothesis of symmetrical technological shocks. We plan to abandon this simplified hypothesis in future work in order to account for asymmetrical technological shocks across firms and sectors. In line with the methodological approach adopted in this work, we intend to do this by relying on empirical evidence based on micro-level data, in line with the findings in Cainelli et al. (2006).

Overall, this work aimed at healing the fracture between Keynesian and neo-Schumpeterian 'lines of thought' (Verspagen 2002) in the belief that more effort should be devoted to integrating - especially in the domain of services these two main theoretical streams. As part of our future research agenda, we intend to explore in more depth growth and changes in the composition of final demand, which, along with the dramatic changes in cross-sectoral intermediate linkages accounted for in the present work, are the ultimate shapers of changes in the structural composition of advanced economies.

Open Access This article is distributed under the terms of the Creative Commons Attribution Noncommercial License which permits any noncommercial use, distribution, and reproduction in any medium, provided the original author(s) and source are credited.

\section{Appendix}

Table 1 Sectors included in the analysis

\begin{tabular}{|c|c|c|}
\hline ISIC Rev.3 & Acronym & Industry \\
\hline $1-14$ & AGRI & $\begin{array}{l}\text { Agriculture, hunting, forestry, fishing, mining, } \\
\text { and quarrying }\end{array}$ \\
\hline $15-16$ & FOOD & Food products, beverage and tabacco \\
\hline $17-19$ & TEXTILE & Textiles, textile products, leather and footwear \\
\hline $20-22$ & WOOD & $\begin{array}{l}\text { Wood, wood products, cork, pulp, paper, } \\
\text { paper products, printing and publishing }\end{array}$ \\
\hline $23-26$ & CHEM & $\begin{array}{l}\text { Chemical, rubber, plastic, fuel products, } \\
\text { and other non-metallic mineral products }\end{array}$ \\
\hline $27-35$ & MACHINERY & $\begin{array}{l}\text { Basic and fabricated metal prod., } \\
\text { machinery and equipments }\end{array}$ \\
\hline $36-37$ & MANEC & Manufacturing n.e.c. \\
\hline $40-45$ & ELEC & Electricity, gas, water and construction \\
\hline $50-55$ & TRADE & Wholesale and retail trade; hotels and restaurants \\
\hline $60-64$ & TRACOM & Transports, storage and communications \\
\hline $65-67$ & FINANCE & Financial intermediation \\
\hline $70-74$ & KIBS & $\begin{array}{l}\text { Real estate; Renting of machinery and equipment; } \\
\text { computer and related; R\&D; business services }{ }^{\mathrm{a}}\end{array}$ \\
\hline 75-99 & SOCIAL & $\begin{array}{l}\text { Community; social; personal and other government } \\
\text { services }\end{array}$ \\
\hline
\end{tabular}

a Business services (74) includes: Legal and Accounting; Engineering; Technical; Consultancy; Marketing; Training; Cleaning; Security 


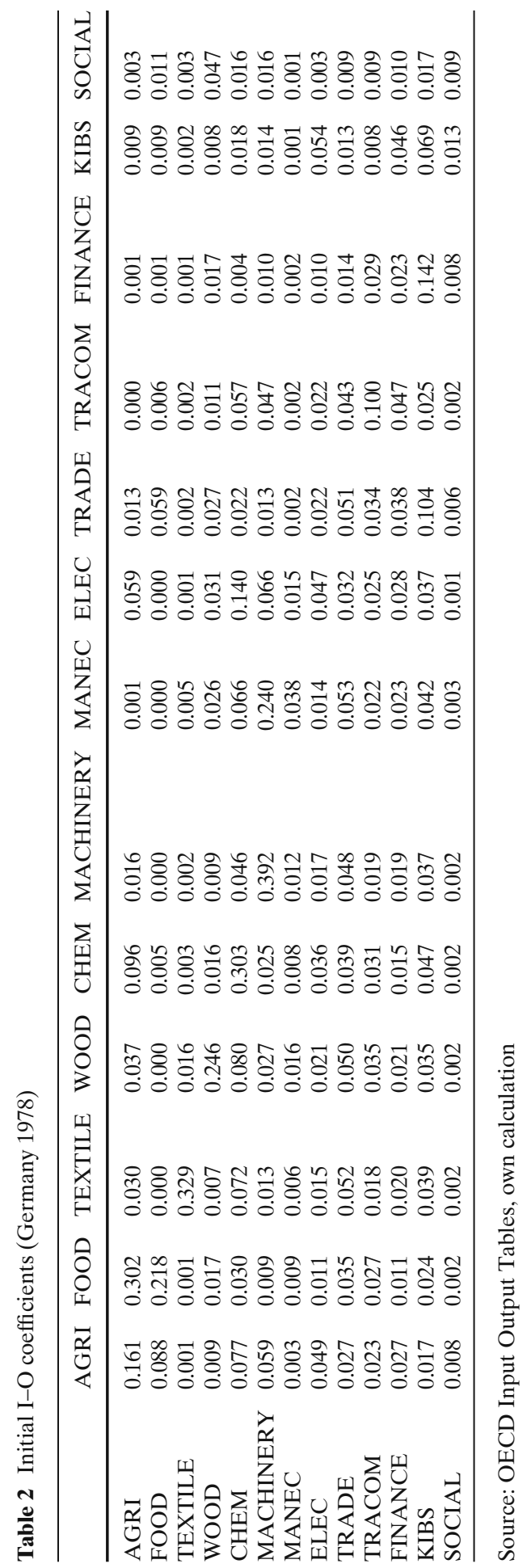


Table 3 Initial values for selected coefficients (Germany 1978)

\begin{tabular}{lrllrr}
\hline & Exports & $\begin{array}{l}\text { Consumption } \\
\text { shares }\end{array}$ & $\begin{array}{l}\text { Import } \\
\text { shares }\end{array}$ & \multicolumn{2}{c}{ K-V coefficients } \\
\cline { 2 - 6 } & \multicolumn{1}{c}{$X_{j, t^{\mathrm{a}}}$} & $c_{j, t^{\mathrm{a}}}$ & $m_{j, t}{ }^{\mathrm{a}}$ & $\lambda_{k}{ }^{\mathrm{b}}$ & $\beta_{k}{ }^{\mathrm{b}}$ \\
\hline AGRI & 9768.69 & 0.008 & 0.395 & 0.872 & -0.002 \\
FOOD & 14510.06 & 0.047 & 0.114 & 0.862 & -0.001 \\
TEXTILE & 16484.99 & 0.019 & 0.353 & 0.475 & 0.034 \\
WOOD & 10152.96 & 0.008 & 0.131 & 0.715 & -0.002 \\
CHEM & 65014.43 & 0.024 & 0.217 & 0.851 & -0.001 \\
MACHINERY & 204944.78 & 0.030 & 0.172 & 0.582 & -0.001 \\
MANEC & 12873.43 & 0.005 & 0.228 & 0.612 & 0.005 \\
ELEC & 3117.50 & 0.012 & 0.005 & 0.469 & -0.021 \\
TRADE & 13869.20 & 0.062 & 0.018 & 0.717 & -0.002 \\
TRACOM & 23830.67 & 0.014 & 0.080 & 0.902 & 0.001 \\
FINANCE & 366.39 & 0.008 & 0.004 & 0.928 & -0.03 \\
KIBS & 7777.17 & 0.054 & 0.030 & 0.217 & 0.004 \\
SOCIAL & 3263.04 & 0.098 & 0.013 & 0.812 & -0.011 \\
\hline
\end{tabular}

Source: a OECD Input Output Tables, own calculation

${ }^{\mathrm{b}}$ OECD STAN, own calculation

\section{References}

Appelbaum E, Schettkat R (1999) Are prices unimportant? The changing structure of industrialised economies. J Post Keynes Econ 21:387-398

Baumol W (1967) Macroeconomics of unbalanced growth: the anatomy of an urban crisis. Am Econ Rev 57:415-426

Baumol W (2001) The growth of service industries. The paradox of exploding costs and persistent demand. In: ten Raa T, Schettkat R (eds) Paradox of the services: exploding costs and persistent demand. Edward Elgar, Aldershot

Baumol W (2008) The two-sided cost disease and its frightening consequences. In: Gallouj F, Djellal F, Gallouj C (eds) Handbook of innovation and services. Edward Elgar, Aldershot (forthcoming)

Baumol W, Bowen W (1966) Performing arts: the economic dilemma. Twentieth Century Found, New York

Cainelli G, Evangelista R, Savona M (2006) Innovation and economic performance in services. A firm-level analysis. Camb J Econ 30:435-458

Chiaromonte F, Dosi G (1993) Heterogeneity, competition, and macroeconomics dynamics. Struct Change Econ Dyn 4(1):39-63

Clark C (1940) The conditions of economic progress. MacMillan, London

Dosi G, Freeman C, Nelson R, Silverberg G, Soete L (1988) Technical change and economic theory. Pinter, London

Fagerberg J (1994) Technology and international differences in growth rates. J Econ Lit 32: $1147-1175$

Fisher A (1935) The clash of progress and security. MacMillan, London

Fisher A (1945) Economic progress and social security. MacMillan, London

Fourastié J (1949) Le Grand Espoir du XX Siècle. PUF, Paris

Fuchs V (1968) The service economy. National Bureau of Economic Research, New York

Gallouj F (2002) Knowledge intensive business services: processing knowledge and producing innovation. In: Gadrey J, Gallouj F (eds) Productivity, innovation and knowledge in services. Edward Elgar, Aldershot

Kaldor N (1957) A model of economic growth. Econ J 70:65-94, December 
Kaldor N (1966) Causes of the slow rate of growth in the United Kingdom. Cambridge University Press, Cambridge

Kox H, Rubalcaba L (2007) Analysing the contribution of business services to european economic growth. Discussion Paper, Bruges European Economics Research Papers (BEER Paper n. 9)

Leontief W (1951) The structure of American economy 1919-1939, 2nd edn. Oxford University Press, New York

Leontief W (1953) Studies in the structure of the American economy. Oxford University Press, New York

Llerena P, Lorentz A (2004) Cumulative causation and evolutionary micro-founded technical change: on the determinants of growth rates differences. Rev Econ 55(6):1191-1214

Miles I (1994) Innovation in services. In: Dodgson M, Rothwell R (eds) Handbook of industrial innovation. Edward Elgar, Cheltenham

Miles I, Kastrinos N, Bilderbeek P, den Hertog P (1995) Knowledge intensive business services users, carriers and sources of innovation. Discussion paper, EIMS - European Innovation Monitoring System

Montobbio F (2002) An evolutionary model of industrial growth and structural change. Struct Change Econ Dyn 13:387-414

Nelson R, Winter S (1982) An evolutionary theory of economic change. Harvard University Press, Cambridge

Parrinello S (2004) The service economy revisited. Struct Change Econ Dyn 15:381-400

Pasinetti L (1973) The notion of vertical integration in economic analysis. Metroeconomica 25:1-29

Pasinetti L (1981) Structural change and economic growth: a theoretical essay on the dynamics of the wealth of the nations. Cambridge University Press, Cambridge

Peneder M, Kaniovsky S, Dachs B (2003) What follows tertiarisation? Structural change and the role of knowledge-based services. Serv Ind J 23:47-66

Pugno M (2006) The service paradox and endogenous economic growth. Struct Change Econ Dyn 17:99-115

Rose A, Casler S (1996) Input-output structural decomposition analysis: a critical reappraisal. Econ Syst Res 8(1):33-62

Savona M, Lorentz A (2005) Demand and technology contribution to structural change and tertiarisation: an input-output structural decomposition analysis. Working papers, LEM, Pisa

Schettkat R, Yocarini L (2006) The shift to services employment: a review of the literature. Struct Change Econ Dyn 17:127-147

Schumpeter J (1934) The theory of economic development. An inquiry into profits, capital, credit, interest and the business cycle. Harvard University Press, Cambridge

Silverberg G, Verspagen B (2005) Evolutionary theorizing on economic growth. In: Dopfer K (ed) The evolutionary foundations of economics. Cambridge University Press, Cambridge, pp 506-539

ten Raa T, Schettkat R (2001) The growth of service industries. The paradox of exploding costs and persistent demand. Edward Elgar, Cheltenham

van Ark B, Inklaar R, McGuckin R (2002) Changing gear'. Productivity, ICT and service industries. Europe and the US. In: Paper for the ZEW Conference on Economics of Information and Communication Technology, Mannheim, June 2002

Verdoorn P (1949) Fattori che regolano lo sviluppo della produttivitá del lavoro. L'Industria 1: $45-53$

Verspagen B (1993) Uneven growth between interdependent economies: evolutionary views on technology gaps, trade and growth. Aldershot, Avenbury

Verspagen B (2002) Evolutionary macroeconomics: a synthesis between neo-schumpeterian and post-keynesian line of thought. Elec J Evol Model Econ Dyn 1007 (http://www. e-jemed.org/1007/index.php)

Verspagen B (2004) Structural change and technology. A long view. Rev Econ 55(6):1099-1126 